\title{
Development of a Simulation-Based Intelligent Decision Support System for the Adaptive Real-Time Control of Flexible Manufacturing Systems
}

\author{
Babak Shirazi $^{1}$, Iraj Mahdavi ${ }^{1}$, Maghsud Solimanpur ${ }^{2}$ \\ ${ }^{1}$ Mazandaran University of Science and Technology, Babol, Iran; ${ }^{2}$ Urmia University, Urmia, Iran. \\ Email: irajarash@rediffmail.com
}

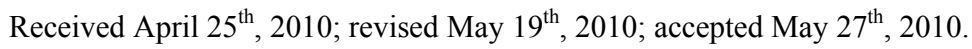

\begin{abstract}
This paper describes a simulation-based intelligent decision support system (IDSS) for real time control of a flexible manufacturing system (FMS) with machine and tool flexibility. The manufacturing processes involved in FMS are complicated since each operation may be done by several machining centers. The system design approach is built around the theory of dynamic supervisory control based on a rule-based expert system. The paper considers flexibility in operation assignment and scheduling of multi-purpose machining centers which have different tools with their own efficiency. The architecture of the proposed controller consists of a simulator module coordinated with an IDSS via a real time event handler for implementing inter-process synchronization. The controller's performance is validated by benchmark test problem.
\end{abstract}

Keywords: Intelligent Decision Support System, Real Time Control, Flexible Manufacturing System, Multi-Purpose Machining Centers

\section{Introduction}

A flexible manufacturing system (FMS) architecture can be characterized as a set of multi-purpose machine tools connected by automatic material handling and tool transportation devices. The material handling system has a mechanism to transport parts between machining centers. Automatic tool transportation devices can also transfer tools among tool magazines and the central tool storage area [1,2]. Any material handling system has a mechanism to transport parts and tools automatically. These systems can transfer tools among tool magazines and the central tool storage area while the system is in operation $[3,4]$. FMSs are essentially more flexible than the conventional manufacturing systems, mainly because of utilizing versatile manufacturing lines, redundant and reconfigurable machines, alternate routings, and flexibility in operation sequencing $[5,6]$.

Due to different operations on a product and machine requirements to process each step of production, it is so hard to control different events that might happened at different cells to achieve best practice of performance criteria [7]. Regarding these considerations, control of these environments plays an essential role at manufacturing systems. Control framework has been studied on FMSs in the literature and there are different methods for selecting the most appropriate control policies at each decision point [8-15]. These strategies deal with the allocation of jobs to multi-purpose machining centers which have to be made in a flexible way. Most of these studies focus on reactive strategies that enable the FMS to better deal with randomness and variability. It means that most of these FMS controllers usually use fixed and offline policies to operate the system. However, these methods do not consider many realistic constraints and dynamic changes such as tool magazine capacity, operative efficiency changes and availability of tools in the part selection and operation assignment problems. These offline methods are mainly categorized into two forms: priori reactive control and the posteriori reactive control methods. The control is planned according to the structural information, forecasts, orders, management rules 
and objectives [16]. The online posteriori control adapted directly to the system for preventive deviations by controlling occurrence of events.

Improving the performance of an FMS supervised by an effective controller is still a complex task that not only is time consuming but also needs much human expertise in decision making [17]. In order to implement an adaptive controller, DSS have become an effective method for their adaptability in controlling complex and dynamic operations [18]. There have been limited investigations on IDSS for controlling such systems as a unified approach. There is a need to construct a framework in which a knowledge-based decision analysis will assist the decision process to improve the FMS control parameters.

An effective approach for reinforcement of IDSS performance is to develop an embedded simulation model that meets the desired objectives of the system [19-22]. Discrete-event simulation is a very powerful tool that can be used to evaluate alternative control policies in the manufacturing system [23-26]. Although the procedure of analyzing simulation results could rely on various guidelines and rules, decision-making still requires significant human expertise and computer resources. To efficiently use simulation in the decision process, integration of IDSS with simulation has been emphasized [27-30]. However, there have been limited investigations on integrating IDSS with the modular simulation languages as a unified approach for controlling manufacturing systems. So FMS control appears to be an excellent area for applying adaptive IDSS simulation-based controller.

This research focuses on developing a simulationbased intelligent expert system with dynamic rules contemplating tool and machine flexibility control. For implementing inter-process synchronization in real-time control of FMS, the proposed IDSS receives online results from simulation module and different scenarios of control parameters with simulation replication action. The outline of the paper is as follows. Section 2 describes adaptive flexibility control on FMS shop floor. Section 3 deals with FMS adaptive controller architecture to build IDSS. Sections 4 present experimental study to validate the effectiveness of the proposed system. Finally, conclusions are made in Section 5.

\section{Adaptive Flexibility Control on FMS Shop Floor}

\subsection{Adaptive Control Mechanism}

Adaptive supervisory implies selection of an appropriate control policy based on the current state of the workcell. Regarding dynamic control of manufacturing systems, jobs are dispatched to machining centers using dispatch- ing rules at the specific moment based on the available information. Afterwards, appropriate tool is mounted in machining center according to the tooling strategy [31]. Because of the flexible characteristics of FMSs, control decisions should be applied as soon as possible based on the real time state of the system. An FMS adaptive controller has to deal with the dynamic environment in which the system operates to seize online machines and tools redundancy capabilities, alternative routing and hazard control remedy.

\subsection{FMS Shop Floor Flexibility Control Functions}

The most commonly accepted definition of flexibility is the ability to take up different positions or alternatively the ability to adopt a range of states [32]. Many different authors have defined many different types of flexibilities (machine, process, product, operation, routing, volume, production and expansion flexibility) in the literature [33-37]. Here we consider the flexibility control function as machine flexibility and tool flexibility. Browne et al. [38] defined machine flexibility as the ease of change to process a given set of part types. Buzacott [39] clarifies machine flexibility as the ability of the system to cope with changes. There are three technical constraints related to a machining center: number and capacity of machine-tools, local input/output buffer (LIB/LOB) size and operative efficiency. Das and Nagendra [40] define machine flexibility of a machining center as the ability of performing more than one type of processing operation efficiently. Therefore, machine flexibility is measured by the number of operations that a workstation processes and the time needed to switch from one operation to another. The more operations a workstation processes and the less time switching takes, the higher the machine flexibility becomes [37]. Figure 1 shows the proposed adaptive flexibility control functions of the FMS shop floor.

As illustrated in Figure 1, tool flexibility can be defined as getting the right tool, to the right place at the right time $[34,41]$. The need for tooling strategies originates from the high variety and number of cutting tools that are typically found in automated manufacturing systems. The adoption of appropriate tool management policies that consider alternative tools allows the desired part mix and quantities to be manufactured efficiently while achieving improved performance [42]. At machine tool level, there are two technical constraints related to tool allocation: tool magazine capacity and tool life. Due to tool magazine capacity, there is a restriction on the number of operations that can be processed in a single tool setup. On the other hand, if tools can be loaded and unloaded while the machine is running, the capacity of the tool magazine can be assumed to be unlimited $[32,43]$. 
Industrial FieldBus
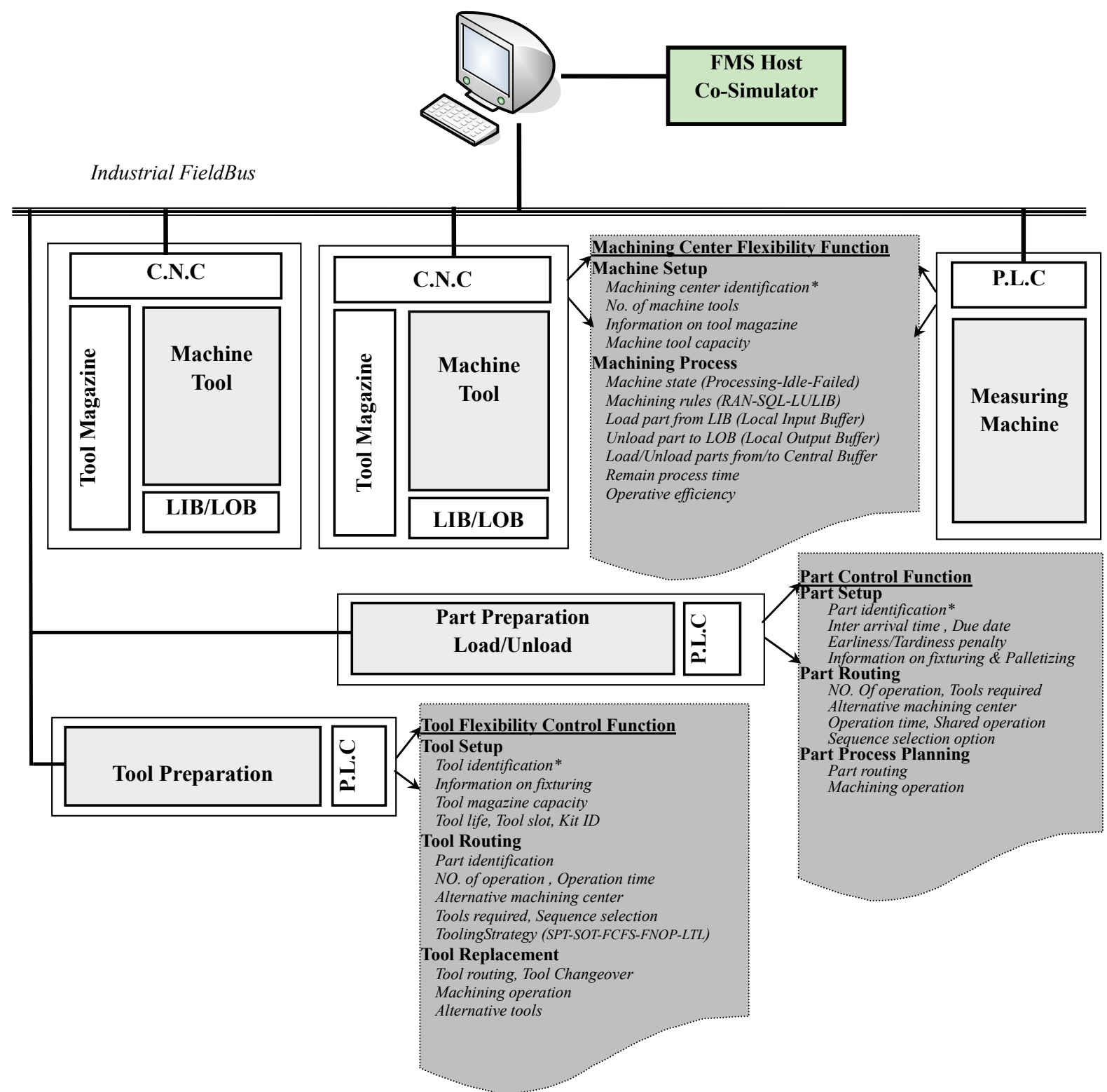

Figure 1. FMS shop floor flexibility control functions

The tool magazine capacity is an influential factor in determining the flexibility of the system. A proper tool management is needed to control processing of parts and enhance the flexibility to variety of parts. It is important to design a tool management control function so that the proper tools are available at the right machine at the desired time for processing of scheduled parts.

The work-order processing and part control system essentially drives other control functions. This module concerns the determination of a subset of part types from a set of part types for processing.

A number of criteria can be used for selecting a set of part types for processing (i.e. due date, inter arrival time, requirement of tools, operation time, shared operation, operations sequence).

\section{FMS Adaptive Controller Architecture}

\subsection{FMS Configuration Parameters}

The following notations and criteria are utilized in developing the rule-based model of the FMS controller addressed in this research. Table 1 represents the notations.

These parameters are defined in such a way that contains information about the previous control functions on a platform of multi-purpose machines. In other words, definition of these parameters considers machine and tool 
Table 1. FMS configuration parameters and performance criteria

\begin{tabular}{|c|c|c|c|}
\hline \multicolumn{4}{|c|}{ FMS configuration parameters } \\
\hline Notation & Definition & Notation & Definition \\
\hline$P_{i}$ & $i$-th production order, $1 \leq i \leq p$ & $O E_{i j k l}$ & Operative efficiency of $O_{i j}$ on $M_{k l}$ \\
\hline$O_{i j}$ & $j$-th operation of order $P_{i}, \quad 1 \leq j \leq n_{i}$ & $D D_{P i}$ & Due date of $P_{i}$ \\
\hline$M / C_{k}$ & $k$-th machining centers, $1 \leq k \leq m$ & $T_{i j}$ & Time for processing operation $O_{i j}$ \\
\hline$M_{k l}$ & $l$-th machine of $M / C_{k}, \quad 1 \leq l \leq L_{k}$ & $\alpha_{i}$ & Penalty weight for $P_{i}$ when $A C T_{i}$ is less than $D D_{P i}$ \\
\hline$I A T_{i}$ & inter arrival time between $P_{i}$ and $P_{i-1}$ & $\beta_{i}$ & Penalty weight for $P_{i}$ when $A C T_{i}$ is greater than $D D_{P i}$ \\
\hline$T M C_{k l}$ & Tool magazine capacity of $M_{k l}$ & $n_{i}$ & The number of $P_{i}$ operations. \\
\hline$T L_{h k l}$ & Tool life of $h$-th tool of $M_{k l}$ (time based) & $R E_{i}$ & The number of operation remain to complete $P_{i}$ \\
\hline$T M_{h k l}$ & $h$-th tool of $M_{k l}$ tool magazine & $\operatorname{Min} U$ & Minimum utilization \\
\hline$M S_{i j}$ & Set of machines which can handle $O_{i j}$ & $\operatorname{Max} U$ & Maximum utilization \\
\hline$L I B_{k l}$ & Local input buffer size of $M_{k l}$ & $S T_{i j}$ & Standard time of $O_{i j}$ with $100 \%$ operative efficiency \\
\hline$L O B_{k l}$ & Local output buffer size of $M_{k l}$ & $T P$ & Throughput \\
\hline PTH & Duration of planning time horizon & $R T O_{i j}$ & Number of required Tool for $O_{i j}$ \\
\hline$t$ & Current time & $E T T_{i j}$ & Elapsed time between $O_{i j}$ and its latter operation \\
\hline \multicolumn{4}{|c|}{ Simulator outputs performance criteria } \\
\hline Notation & Definition & Notation & Definition \\
\hline$T B D_{k l}$ & Time between departures on $M_{k l}$ & $T I T_{k l}$ & Total idle time of $M_{k l}$ \\
\hline$A C T_{i}$ & Actual cycle time of order $P_{i}$ & $T W T_{i}$ & Total waiting time of $P_{i}$ \\
\hline$Z_{i}$ & Total penalty of $P_{i}$ & $M U_{k l}$ & Machine $M_{k l}$ utilization \\
\hline$O S_{i}(t)$ & Set of operations of $P_{i}$ processed until $t$ & $O S_{k l}(t)$ & Set of operations processed on $M_{k l}$ until $t$ \\
\hline$Q M_{k l}$ & Queue size of $M_{k l}$ & $C T_{k l}$ & Completion time in $M_{k l}$ \\
\hline$T U_{h k l}$ & Tool usage of $h$-th tool of $M_{k l}$ (time based) & $B U_{k l}$ & Buffer usage of $M_{k l}$ \\
\hline
\end{tabular}

Table 2. Binary control flags

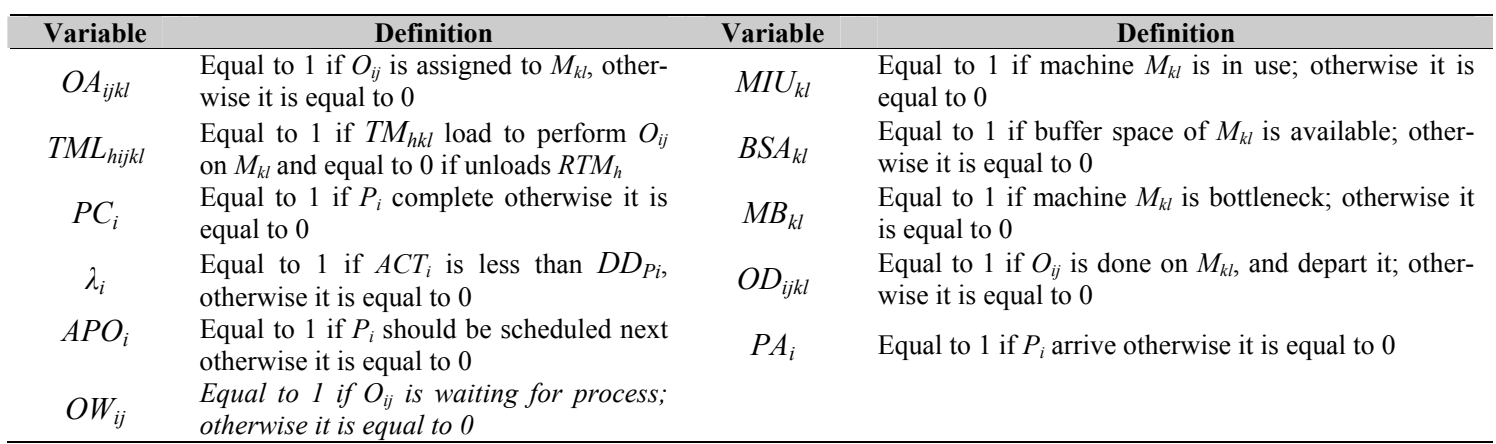

flexibility characteristics of an FMS. Table 2 shows the binary control flags (BCF's).

\subsection{Simulation-Based Intelligent Decision Support System}

Figure 2 shows the combination between simulation and intelligent decision support system as for FMS adaptive control. The figure shows the cooperation between IDSS and the simulator module. The current configuration parameters of the FMS are read by user interface and are used as the input data to build conceptual model. The simulation model will evaluate the current shop performance, such as actual cycle time, tool and buffer utilization. This process continues until a satisfying and controllable shop floor configuration is reached.
The system presents details of the architecture, components and functions of a FMS decision-making controller. The proposed controller consists of a simulator model coordinate rule based IDSS with a real time mechanism. The simulation output data are fed to the knowledge-based system as input data. The rule-based IDSS analyzes output of simulation model to control the real-time status of FMS. Once the IDSS makes recommendations, the simulation model is adjusted accordingly and the process is repeated. The simulation and IDSS components cooperate with each other until the control goals are achieved. Since the primary objective is to improve the throughput of the shop floor, a simulation analysis assisted by decision process is carried out. The status of the cell, machines, part orders, the availability 


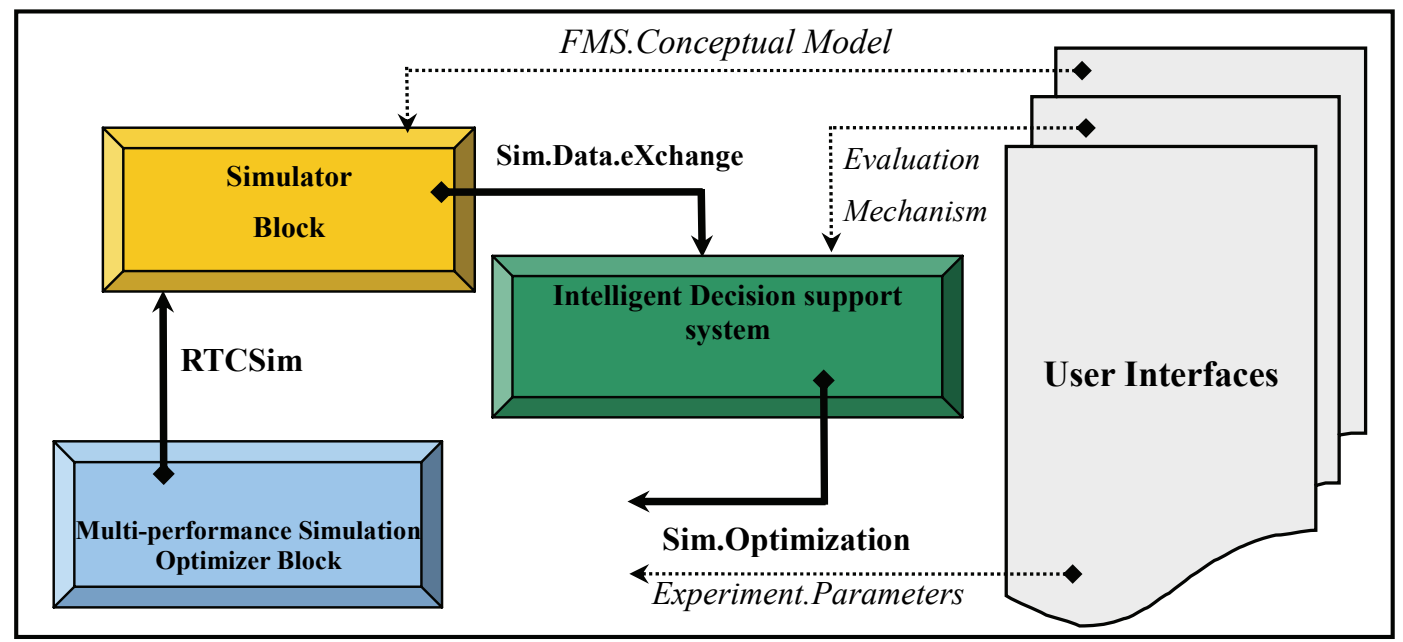

Figure 2. The structure of simulation-based IDSS for FMS adaptive control

of operators and system control flags are recorded in separate databases. Sequence of jobs is used to control the flow of parts through the system. The first step to estimate the performance criteria is assigning the operations to machines and scheduling the operations on each machine.

The above posteriori adaptive control mechanism employs a simulator block to predict different performance criteria of the FMS conceptual model. The simulator contains the discrete event simulation model and is able to measure several FMS performance criteria depending on the different inputs. The simulation results are then forwarded between external interfaces belonging to different external models. On the other hand, these interfaces han- dle the necessary communications with the simulation and coordinate IDSS control signal transformations into the simulator.

Sequence of jobs is used to control the flow of parts through the system. The first step to estimate the performance criteria of FMS is assigning the operations $O_{i j}$ to machining centers and extracting the set $O S M_{k l}(t)$ includes operations processed on $M / C_{k}$ until $t$. The real time adaptive control framework is based on affiliating all current events and expected future event to a time tag for process synchronization. The following pseudo-code shows the initialization phase of the simulation in order to configure the FMS conceptual model.

The initialization phase should be run in execution

FMSConfigParam()

Read Number of parts, machining centers and planning horizon ( $p, m, P T H)$;

For $i:=1$ to $p$ Read Number of parts operations and due date $\left(n_{i}, D D_{P i}, I A T_{i}, \alpha_{i}, \beta_{i}\right)$;

For $k:=1$ to $m$ Read Number of machines at each machining centers $\left(L_{k}\right)$;

For $k:=1$ to $m$ initialize Machining Centers Resources $M / C_{k}$, Capacity;

For $k:=1$ to $m$

For $l:=1$ to $L_{k}$ initialize Machine Tools, Tool magazine and buffers $\left(M T_{k l}, T M C_{k l}, L I B_{k l}, L O B_{k l}\right)$;

For $i:=1$ to $p$

For $j:=1$ to $n_{i}$

Initialize queue used to hold part operations $\left(O_{i j}\right.$ (Process.Queue));

Read (processing time of each operation $\left(O_{i j}, T_{i j}, S T_{i j}, M S_{i j}, E T T_{i j}, R T O_{i j}\right)$;

InitTime(t); (Initialize simulation current time)

RealTimeInitialize(t); (Initialize inter-process synchronization)

mode using the function RealTimeInitialize( $t$ ) to synchronize simulation logic with an external process of FMS controller system. The module RTCSim $(t)$ represents FMS events simulation to handle machine and tool flexibility.

The simulation clock is set to the real-time clock of the operating FMS system and all other simulation processes are initiated by $\operatorname{InitProcess}\left(O_{i j}\right)$. Because of the randomness of processing times in each replication, the expectations of system outputs are estimated by sample means. The function $T A V G\left(A C T_{i}, T U_{h k l}, B U_{k l}\right)$ records the values of system outputs throughout each replication and finally estimates the expectation of these statistics 


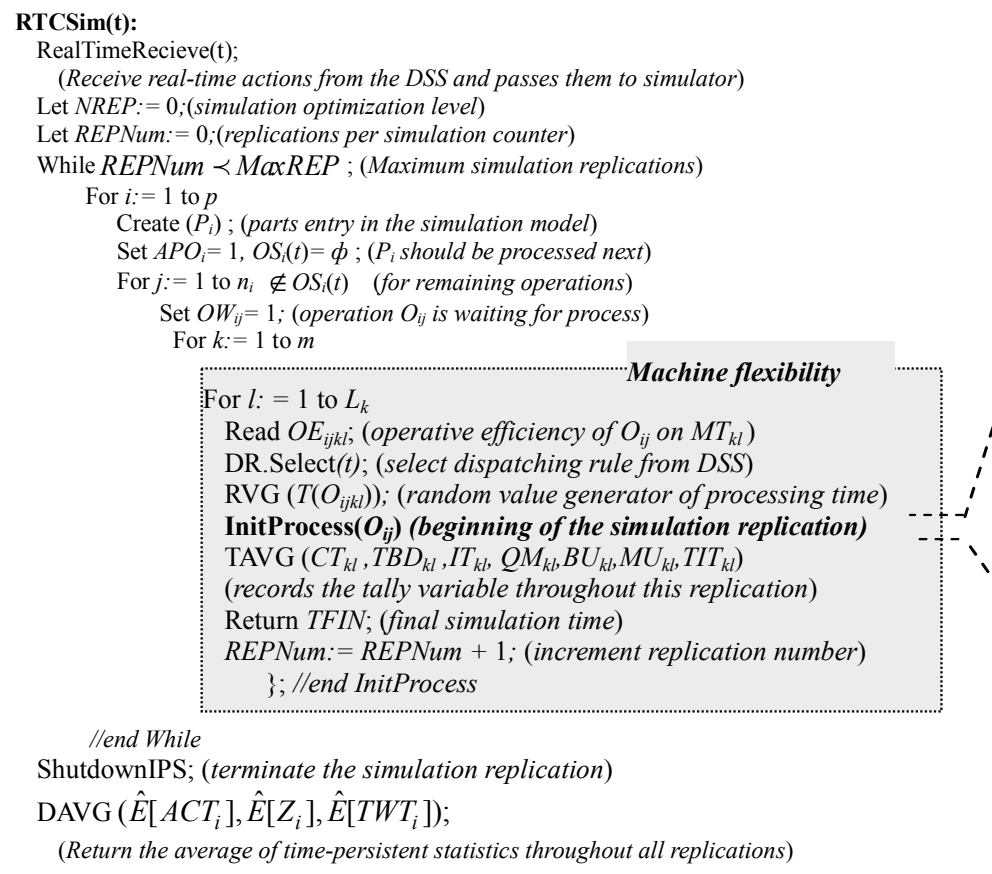

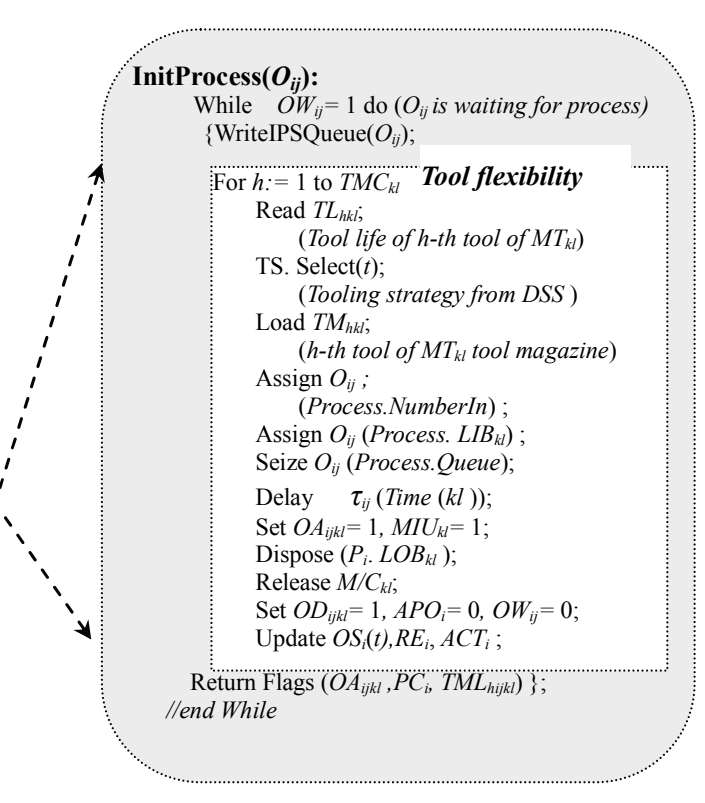

adaptive controller with this structure allows modeling of synchronization mechanism between FMS entities and transmission times for messages exchanged between the IDSS and simulator.

Figure 3 schematically describes the inter-process synchronization between different components of cosimulator. The approach for adaptive controller designing is built around the theory of supervisory control based on exchanging simulation outputs with an event-condition-action real time system. The proposed system uses a posteriori adaptive control mechanism that also is an online control method acting after the event occurs versus such popular reactive control method.

The simulator can trigger the rule-based IDSS to generate the appropriate control policy. The simulator block sends messages to the external rule-based system to indicate simulated results from FMS by RealTimeSend(). The rule-based IDSS interprets these results and sends appropriate action messages back to the simulator and user to indicate the instructions to be done.

\subsection{Rule Production for FMS Real Time Simulation-Based Controller}

The IDSS collect the facts into appropriate data base using CollectFact(), which is then used for inference by simulation outputs in feed forwarding reasoning. The control framework is implemented by integration of the adaptive control rules and real time simulator for enforcing dynamic strategies of FMS shop floor control. In order to strengthen the expert system reasoning, knowledge-elicit- 


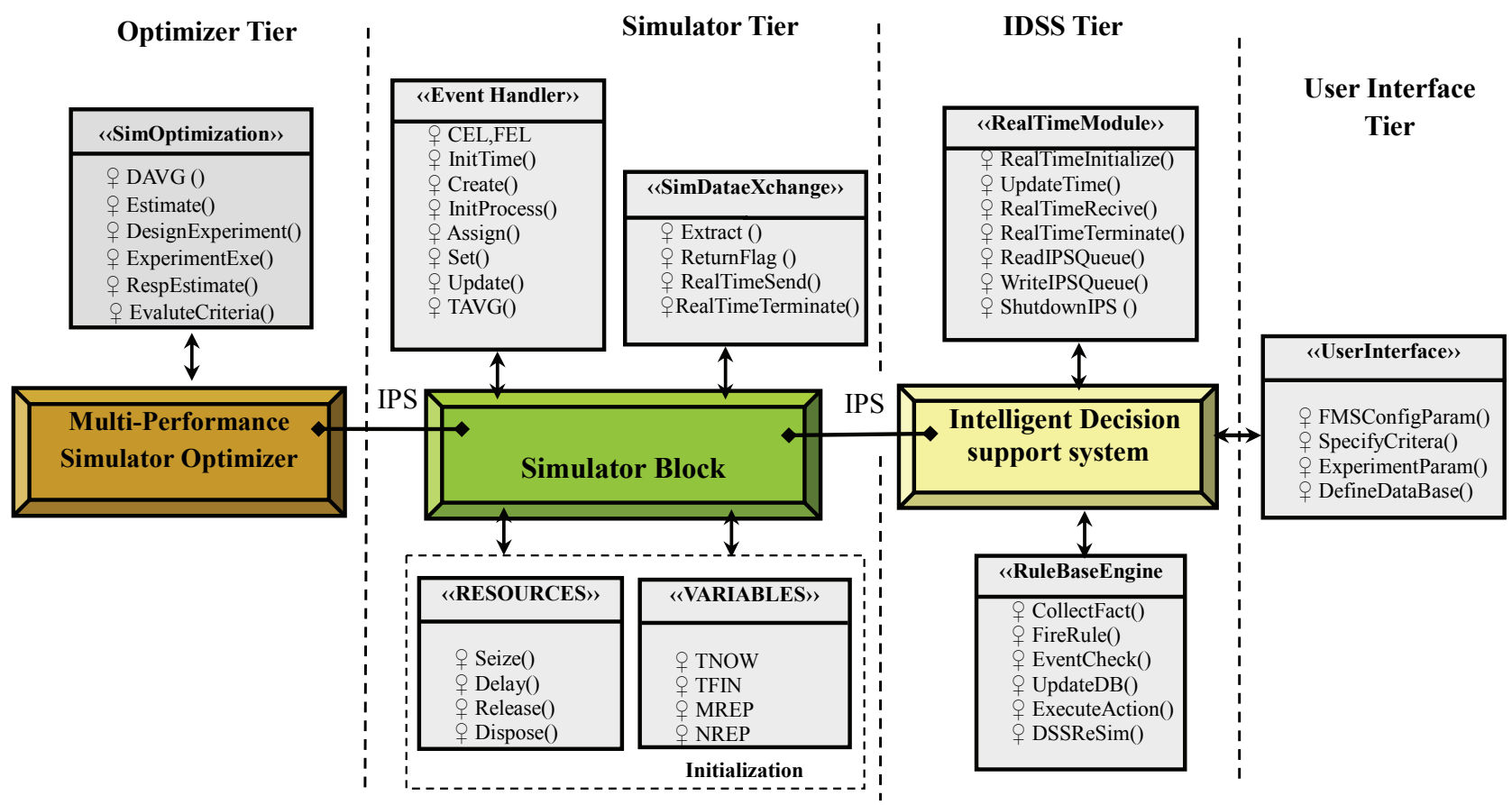

Figure 3. Real time simulation data exchange via inter-process synchronization

tation techniques are used for preventing ineffective redundancy at concurrent firing of rules and high degree of parallelism. This knowledge-based IDSS is aimed at providing a powerful control on different operations of FMS. It acts as a cell manager which may work alongside the operating cell-oriented part and tool management system. These sections describe the knowledge representation through a set of control rules. Design of IDSS controller focuses on the development of appropriate Event-Condition-Action (ECA) rules for tuning control parameters. These rules are formulated by the techniques of data gathering and knowledge elicitation to construct IDSS. The IDSS is able to obtain feedback results from the on-line system of simulator. These results are very significant and let the expert system to re-simulate if the performance criteria are not desirable.

The rules applied in this paper are structured in the following form and consist of three segments: event type, condition and action:

$$
\begin{aligned}
& \text { When 〈Event } \left.{ }_{1}, \text { Event }_{2}, \text { Event }_{3}, \ldots\right\rangle \\
& \text { If 〈Condition } \left., \text {, Condition }, \text { Condition }_{3}, \ldots\right\rangle \text { 〉 } \\
& \text { Then } \left.\text { Action }_{1}, \text { Action }_{2}, \text { Action }_{3}, \ldots\right\rangle
\end{aligned}
$$

Event type: This tag specifies that analysis of condition should be done once the events take place.

Condition: This segment of ECA rules specifies a list of conditions. In order to trigger an action rule, all conditions should be satisfied. These conditions refer to a logical assertion of the FMS states extracted by the simulator module RTCSim $(t)$.
Action: This segment specifies actions which may consist of a list of operations. Whenever an action rule is triggered by an event, the operations being in its action list will be initiated sequentially. The proposed rulebased system for manufacturing execution system provides the parts sequence list to the multi-purpose machines available and then the operation assignment and task proportions of parts on related machines. The output can be manipulated by changing the rules and strategies entered at the expert system query stage. Table 3 illustrates MES control function about dispatching rules.

For each part $P_{i}$ the slack index is defined as: Slack $_{i}=D D_{P i}-\sum_{j=1}^{n_{i}} S T_{i j}-t, \forall i$. The function Sort(array) finds the maximum or minimum value in the array and the binary flag $A P O_{i}$ specifies the next scheduled part. Table 4 illustrates MES control function for machining rules in the FMS.

The binary flag $O A_{i j k l}$ specifies the assignment of operation $O_{i j}$ to machine $M_{k l}$. Table 5 illustrates MES control function for tooling strategy in the FMS.

Operative efficiency of doing operation $O_{i j}$ on $M_{k l}$ is defined as $O E_{i j k l}$ and thus tool usage can be considered as $T U_{h k l}=T_{i j} \times\left(1+O E_{i j k l}\right) ; \forall h, k, l$. For each executable operation $O_{i j}$, the proportion of $O_{i j}$ performed on $M_{k l}$ is denoted as $\rho_{i j k l}(t), \quad 0 \leq \rho_{i j k l} \leq 1$. IDSS monitors all events and states transition of FMS by considering $\rho_{i j k l}$ to 
Table 3. MES control function (dispatching rules)

\begin{tabular}{|c|c|c|c|}
\hline \multicolumn{4}{|c|}{ MES Control Function: Dispatching Rules } \\
\hline Dispatching Rule & When [Event] & If (Condition) & Action \\
\hline Shortest Processing Time & $\begin{array}{c}t \neq 0 \\
\text { RealTimeRecieve() }\end{array}$ & $\operatorname{DR} \cdot \operatorname{Select}(t)=S P T$ & $\operatorname{Sort}\left(S T_{i j}\right) \forall i \forall j ; A P O{ }_{i}=1 ;$ \\
\hline First Come First Serve & $\begin{array}{c}t \neq 0 \\
\text { RealTimeRecieve() }\end{array}$ & DR.Select $(t)=F C F S$ & $\operatorname{Sort}\left(I A T_{i}\right) \forall i ; \quad A P O_{i}=1$ \\
\hline $\begin{array}{l}\text { Operation with Least } \\
\quad \text { Slack }\end{array}$ & $\begin{array}{c}t \neq 0 \\
\text { RealTimeRecieve() }\end{array}$ & $\begin{array}{l}\text { DR.Select }(t)=S L A C K \\
P C_{i}=0 \& \& \text { Slack }_{i} \prec 0\end{array}$ & $\operatorname{Sort}_{\left(\left|\operatorname{Slack}_{i}\right|\right) \forall i ; \quad A P O}{ }_{i}=1 ;$ \\
\hline $\begin{array}{c}\text { Slack Per Remaining } \\
\text { Work }\end{array}$ & $\begin{array}{c}t \neq 0 \\
\text { RealTimeRecieve() }\end{array}$ & $\begin{array}{c}\text { DR.Select }(t)=S / R M O P \\
P C_{i}=0 \& \& \text { Slack }_{i} \prec 0\end{array}$ & $\operatorname{Sort}\left(\mid\right.$ Slack $\left._{i} \mid / R E_{i}\right) \forall i \forall j ; A P O O_{i}=1 ;$ \\
\hline $\begin{array}{c}\text { Slack Per Remaining } \\
\text { Work }\end{array}$ & $\begin{array}{c}t \neq 0 \\
\text { RealTimeRecieve() }\end{array}$ & $\begin{array}{c}\text { DR.Select }(t)=S / R M W K \\
P C_{i}=0 \& \& \text { Slack }_{i} \prec 0\end{array}$ & $\operatorname{Sort}\left(\mid\right.$ Slack $\left._{i} \mid / \sum_{j} S T_{i j}\right) \forall i \forall j ;, A_{i}=1 ;$ \\
\hline Earliest Due Date & $\begin{array}{c}t \neq 0 \\
\text { RealTimeRecieve() }\end{array}$ & $D R \cdot$ Select $(t)=E D D$ & $\operatorname{Sort}\left(D D_{P i}\right) \forall i ; A P O_{i}=1 ;$ \\
\hline
\end{tabular}

Table 4. MES control function (machining rules)

\begin{tabular}{|c|c|c|c|}
\hline \multicolumn{4}{|c|}{ MES Control Function: Machining Rules } \\
\hline Machining Rule & When [Event] & If (Condition) & Action \\
\hline Random Selection & $\begin{array}{c}t \neq 0 \\
\text { RealTimeRecieve() }\end{array}$ & $\begin{array}{c}\text { MR.Select }(t)=R A N \\
A P O_{i}=1\end{array}$ & $\operatorname{Sort}\left(\right.$ Rand $\left.M_{k l}\right) \forall k \forall l ; O A{ }_{i j k l}=1$; \\
\hline Shortest Queue Length & $\begin{array}{c}t \neq 0 \\
\text { RealTimeRecieve() }\end{array}$ & $\begin{array}{c}M R \cdot \operatorname{Select}(t)=S Q L \\
\operatorname{APO}_{i}=1\end{array}$ & $\operatorname{Sort}\left(Q M_{k l}\right) \forall k \forall l ; O A_{i j k l}=1$ \\
\hline Lowest Utilized Buffers & $\begin{array}{c}t \neq 0 \\
\text { RealTimeRecieve() }\end{array}$ & $\begin{array}{c}\text { MR.Select }(t)=L U B \\
\text { APO }_{i}=1\end{array}$ & $\operatorname{Sort}\left(B U_{k l}\right) \forall k \forall l ; O A_{i j k l}=1$ \\
\hline
\end{tabular}

Table 5. MES control function (tooling strategy)

\begin{tabular}{|c|c|c|c|}
\hline \multicolumn{4}{|c|}{ MES Control Function: Tooling Strategy } \\
\hline Tooling Strategy $=$ TS & When [Event] & $\begin{array}{c}\text { If } \\
\text { (Condition) }\end{array}$ & Action \\
\hline Shortest Operation & $t \neq 0$ & $T S . S e l e c t(t)=S O T$ & $\operatorname{Sort}\left(S T_{i j}\right) \forall i \forall j ;$ AssignTool $\left(T M_{h k l}, O_{i j}\right) \forall i \forall j ;$ \\
\hline Time & RealTimeRecieve() & $O A_{i j k l}=1$ & UpdateToolMag $\left(M_{k l}\right)$ \\
\hline $\begin{array}{c}\text { Shortest Processing } \\
\text { Time }\end{array}$ & $\begin{array}{c}t \neq 0 \\
\text { RealTimeRecieve() }\end{array}$ & $\begin{array}{c}T S . \text { Select }(t)=S P T \\
O A_{i j k l}=1\end{array}$ & $\begin{array}{c}\operatorname{Sort}\left(D D_{P i}\right) \forall i ; \text { AssignTool }\left(T_{h k l}, P_{i}\right) \forall i \\
\text { UpdateToolMag }\left(M_{k l}\right)\end{array}$ \\
\hline First Come First Serve & $\begin{array}{c}t \neq 0 \\
\text { RealTimeRecieve() }\end{array}$ & 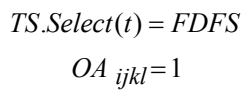 & $\begin{array}{c}\operatorname{Sort}\left(I A T_{i}\right) \forall i ; \text { AssignTool }\left(T M_{h k l}, P_{i}\right) \forall i \forall j ; \\
\text { UpdateToolMag }\left(M_{k l}\right) ;\end{array}$ \\
\hline
\end{tabular}

dynamically rebuild new configuration and replicate simulation module $\operatorname{RTCSim}(t)$. Table 6 contains the rules for control of transition of different states in FMS, bottleneck detection and resolving, assigning operation to a non-bottleneck machining centers.

For each part $P_{i}$ actual cycle time is defined as: $A C T_{i}=\sum_{j \in O S_{k l}}\left(E T T_{i j}+\frac{\rho_{i j k l} \times S T_{i j}}{O E_{i j k l}}\right)$ and the penalty is defined as:

$Z_{i}=\sum_{i=1}^{p}\left[\alpha_{i} \lambda_{i}\left(D D_{P_{i}}-A C T_{i}\right)+\beta_{i}\left(1-\lambda_{i}\right)\left(A C T_{i}-D D_{P_{i}}\right)\right]$

\section{Experimental Study}

The problem presented has been adopted in this paper to validate the proposed method by Sarin and Chen [43]. The model presents machine loading and tool allocation problem in FMS with tool life and magazine capacity. The FMS model includes tool and machine alternatives. The experiment was done on a FMS with four machining centers. Tables $\mathbf{7}$ and $\mathbf{8}$ show tool-operation and machine -tool compatibility.

Table 9 represents the machining time of operations on alternative tools. 
Table 6. MES control function

\begin{tabular}{|c|c|c|c|}
\hline \multicolumn{3}{|c|}{ MES Control Function: States, Bottleneck, Assigning } & \multirow{14}{*}{ 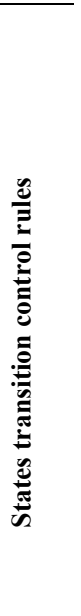 } \\
\hline When [Event] & If $($ Condition) & Action & \\
\hline$t \neq 0$ & $M I U_{k l}=0 ; \forall k \forall l$ & Initialization(initial config. parameters); & \\
\hline$P A=1 \cdot \forall i$ & & DefineDB();SpecifyCriteria ()$; R T C \operatorname{Sim}(t)$ & \\
\hline$P A_{i}=1 ; \nabla \imath$ & & UpdateTime $(t) ;$ SimDataeXchange(IDSS); & \\
\hline$t \neq 0$ & $M B_{k l}=0 ; \exists ! k, l, \quad P A_{i}=1$ & RealTimeRecieve $\left(O S_{k l}(t), O S_{i}(t), \rho_{i j k l}(t), B C F\right)$ & \\
\hline \multicolumn{3}{|l|}{$\operatorname{ReadIPSQueue}\left(O_{i j}\right)$} & \\
\hline$t \neq 0$ & $M I U_{k l}=1 ; \forall k, l \quad B S A_{k l}=0 ; P C_{i}=0$ & \multirow{2}{*}{$\begin{array}{l}\text { RealTimeRecieve }\left(O S_{k l}(t), O S_{i}(t), \rho_{i j k l}(t), B C F\right) \\
\text { UpdateTime }(t)\end{array}$} & \\
\hline $\operatorname{ReadIPSQueue}\left(O_{i j}\right)$ & & & \\
\hline & $M I U_{k l}=0 ; \exists k, l \quad B S A_{k l}=1$ & $M I U_{k l}=1$ & \\
\hline $\begin{array}{l}t \neq 0 \\
\text { ReadIPSOueue }\left(O_{i i}\right)\end{array}$ & $O A_{i j k l}=1 ; \forall j \notin O S_{i}(t) ; P C_{i}=0$ & RealTimeRecieve $\left(O S_{k l}(t), O S_{i}(t), \rho_{i j k l}(t), B C F\right)$ & \\
\hline & & UpdateTime $(t)$ & \\
\hline$t \neq 0$ & $M I U_{k l}=0 ; \exists k, l \quad B S A_{k l}=0 ; \quad P C_{i}=0$ & RealTimeRecieve $\left(O S_{k l}(t), O S_{i}(t), \rho_{i j k l}(t), B C F\right)$ & \\
\hline ReadIPSQueue $\left(O_{i j}\right)$ & & UpdateTime $(t)$ & \\
\hline $\begin{array}{l}t \neq 0 \\
\text { RealTimeRecieve() }\end{array}$ & $n\left[O S_{k l}(t)\right] \succ\left(\sum_{i=1}^{p} n_{i}\right) / L_{K} ; \exists k, l$ & $M B_{k l}=1$ & \multirow{5}{*}{ 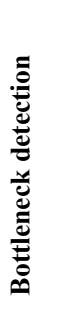 } \\
\hline $\begin{array}{l}t \neq 0 \\
\text { RealTimeRecieve() }\end{array}$ & $T B D_{k 1} \succ(P T H / M i n U) ; \forall k, \quad M I U_{k l}=1$ & $M B_{k l}=1$ & \\
\hline$t \neq 0$ & {$\left[\left(T B D_{k l} \succ T B D_{k(l-1)}\right) \& \&\left(U_{k l} \prec U_{k(l-1)}\right)\right]$} & $M B_{k l}=1$ & \\
\hline RealTimeRecieve() & $M I U_{k l}=1$ & & \\
\hline \multicolumn{3}{|l|}{ RealTimeRecieve() } & \\
\hline \multirow{3}{*}{$\begin{array}{l}t \neq 0 \\
\text { RealTimeRecieve() }\end{array}$} & $M B_{k l}=0 \& \& M I U_{k l}=0 ; \exists k, l$ & $M I U_{k l}=1$ & \multirow{9}{*}{ 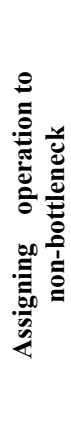 } \\
\hline & $O A_{i j k l}=1 ; \forall j \notin O S_{i}(t)$ & RealTimeSend $\left(O S_{k l}(t), O S_{i}(t), \rho_{i j k l}(t), B C F\right)$ & \\
\hline & & UpdateTime $(t) ;$ SimDataeXchange(IDSS); & \\
\hline & $P C_{i}=0 ; \forall i$ & $O A_{i j k l^{\prime}}=1 ; \forall l^{\prime} \neq l$ & \\
\hline $\begin{array}{l}t \neq 0 \\
\text { RealTimeRecieved }\end{array}$ & $M B_{k l}=1$ & RealTimeSend $\left(O S_{k l}(t), O S_{i}(t), \rho_{i j k l}(t), B C F\right)$ & \\
\hline & & UpdateTime $(t)$; SimDataeX change (IDSS ); & \\
\hline & $\left(M U_{k l} \prec M U_{k^{\prime} l^{\prime}} ; \exists k, k^{\prime}, l, l^{\prime}\right) \|\left(M U_{k l} \prec \operatorname{Min} U\right) ;$ & $O A_{i j k l}=1 ; \forall j \notin O S_{i}(t) ; \quad M I U_{k l}=1$ & \\
\hline $\begin{array}{l}t \neq 0 \\
\text { RealTimeRecieve() }\end{array}$ & $M U_{k l}=M U_{k^{\prime} l^{\prime}}=0 ; \exists k, k^{\prime}, l, l^{\prime} ; P C_{i}=0$ & RealTimeSend $\left(O S_{k l}(t), O S_{i}(t), \rho_{i j k l}(t), B C F\right)$ & \\
\hline & & UpdateTime $(t) ;$ SimDataeXchange(IDSS); & \\
\hline
\end{tabular}

Table 7. Tool-operation compatibility

\begin{tabular}{|c|c|c|c|c|c|c|c|c|c|c|c|c|c|c|c|c|c|c|c|c|c|}
\hline \multicolumn{2}{|c|}{ Part/Tool } & \multirow{2}{*}{$\begin{array}{c}1 \\
1\end{array}$} & \multirow{2}{*}{$\begin{array}{l}2 \\
1\end{array}$} & \multirow{2}{*}{$\begin{array}{l}3 \\
0\end{array}$} & \multirow{2}{*}{$\begin{array}{l}4 \\
0\end{array}$} & \multirow{2}{*}{$\begin{array}{l}5 \\
0\end{array}$} & \multirow{2}{*}{$\begin{array}{l}\mathbf{6} \\
0\end{array}$} & \multirow{2}{*}{$\begin{array}{c}7 \\
0\end{array}$} & \multirow{2}{*}{$\begin{array}{c}8 \\
0\end{array}$} & \multirow{2}{*}{$\begin{array}{l}9 \\
0\end{array}$} & \multirow{2}{*}{$\begin{array}{r}10 \\
0\end{array}$} & \multirow{2}{*}{$\begin{array}{r}11 \\
0\end{array}$} & \multirow{2}{*}{$\begin{array}{r}12 \\
0\end{array}$} & \multirow{2}{*}{$\begin{array}{r}13 \\
0\end{array}$} & \multirow{2}{*}{$\begin{array}{r}14 \\
0\end{array}$} & \multirow{2}{*}{$\begin{array}{r}15 \\
0\end{array}$} & \multirow{2}{*}{$\begin{array}{r}16 \\
0\end{array}$} & \multirow{2}{*}{$\begin{array}{r}17 \\
0\end{array}$} & \multirow{2}{*}{$\begin{array}{r}18 \\
0\end{array}$} & \multirow{2}{*}{$\begin{array}{r}19 \\
0\end{array}$} & \multirow{2}{*}{$\begin{array}{r}20 \\
0\end{array}$} \\
\hline $\mathbf{P}_{1}$ & $\mathbf{O}_{11}$ & & & & & & & & & & & & & & & & & & & & \\
\hline & $\mathbf{O}_{12}$ & 0 & 0 & 0 & 1 & 0 & 0 & 1 & 0 & 0 & 0 & 0 & 0 & 0 & 0 & 0 & 0 & 0 & 0 & 0 & 0 \\
\hline & $\mathbf{O}_{13}$ & 0 & 0 & 0 & 0 & 0 & 1 & 0 & 0 & 0 & 0 & 0 & 0 & 0 & 0 & 0 & 0 & 0 & 0 & 0 & 0 \\
\hline & $\mathbf{O}_{14}$ & 0 & 0 & 0 & 0 & 0 & 0 & 0 & 0 & 0 & 1 & 0 & 0 & 1 & 0 & 0 & 0 & 0 & 0 & 0 & 0 \\
\hline \multirow[t]{4}{*}{$\mathbf{P}_{2}$} & $\mathbf{O}_{21}$ & 1 & 0 & 1 & 0 & 0 & 0 & 0 & 0 & 0 & 0 & 0 & 0 & 0 & 0 & 0 & 0 & 0 & 0 & 0 & 0 \\
\hline & $\mathbf{O}_{22}$ & 0 & 0 & 0 & 0 & 0 & 0 & 0 & 1 & 0 & 0 & 0 & 0 & 0 & 0 & 0 & 1 & 0 & 0 & 0 & 0 \\
\hline & $\mathbf{O}_{23}$ & 0 & 0 & 0 & 0 & 0 & 0 & 0 & 0 & 0 & 1 & 0 & 0 & 0 & 0 & 0 & 0 & 1 & 0 & 0 & 0 \\
\hline & $\mathrm{O}_{24}$ & 0 & 0 & 0 & 1 & 0 & 0 & 0 & 0 & 0 & 0 & 0 & 1 & 0 & 0 & 0 & 0 & 0 & 0 & 0 & 0 \\
\hline \multirow[t]{4}{*}{$\mathbf{P}_{3}$} & $\mathbf{O}_{31}$ & 0 & 0 & 0 & 0 & 0 & 0 & 0 & 0 & 0 & 0 & 0 & 1 & 0 & 0 & 1 & 0 & 0 & 0 & 0 & 0 \\
\hline & $\mathrm{O}_{32}$ & 0 & 0 & 0 & & 0 & 0 & 0 & 0 & 1 & 0 & 0 & 0 & 0 & 0 & 0 & 0 & 0 & 1 & 0 & 0 \\
\hline & $\mathbf{O}_{33}$ & 0 & 0 & 0 & 0 & 0 & 0 & 0 & 0 & 0 & 0 & 1 & 0 & 0 & 0 & 0 & 0 & 0 & 0 & 1 & 0 \\
\hline & $\mathbf{O}_{34}$ & 0 & 0 & 1 & 0 & 0 & 0 & 0 & 0 & 0 & 0 & 0 & 0 & 0 & 1 & 0 & 0 & 0 & 0 & 0 & 0 \\
\hline \multirow[t]{5}{*}{$\mathbf{P}_{4}$} & $\mathbf{O}_{41}$ & 0 & 1 & 0 & 1 & 0 & 0 & 0 & 0 & 0 & 0 & 0 & 0 & 0 & 0 & 0 & 0 & 0 & 0 & 0 & 0 \\
\hline & $\mathbf{O}_{42}$ & 0 & 0 & 0 & 0 & 1 & 0 & 0 & 0 & 0 & 0 & 0 & 0 & 0 & 0 & 0 & 0 & 0 & 0 & 0 & 1 \\
\hline & $\mathbf{O}_{43}$ & 0 & 0 & 0 & 0 & 0 & 0 & 0 & 0 & 0 & 0 & 0 & 0 & 1 & 1 & 0 & 0 & 0 & 0 & 0 & 0 \\
\hline & $\mathbf{O}_{44}$ & 0 & 0 & 0 & 0 & 0 & 1 & 1 & 0 & 0 & 0 & 0 & 0 & 0 & 0 & 0 & 0 & 0 & 0 & 0 & 0 \\
\hline & Tool life & 25 & 21 & 25 & 20 & 22 & 25 & 25 & 22 & 20 & 25 & 18 & 20 & 21 & 25 & 17 & 20 & 20 & 21 & 22 & 24 \\
\hline
\end{tabular}


Table 8. Machine-tool compatibility

\begin{tabular}{cccccccccccccccccccccc}
\hline Machine/Tool & $\mathbf{1}$ & $\mathbf{2}$ & $\mathbf{3}$ & $\mathbf{4}$ & $\mathbf{5}$ & $\mathbf{6}$ & $\mathbf{7}$ & $\mathbf{8}$ & $\mathbf{9}$ & $\mathbf{1 0}$ & $\mathbf{1 1}$ & $\mathbf{1 2}$ & $\mathbf{1 3}$ & $\mathbf{1 4}$ & $\mathbf{1 5}$ & $\mathbf{1 6}$ & $\mathbf{1 7}$ & $\mathbf{1 8}$ & $\mathbf{1 9}$ & $\mathbf{2 0}$ \\
\hline $\mathbf{M}_{\mathbf{1 1}}$ & 1 & 0 & 1 & 0 & 1 & 0 & 1 & 0 & 0 & 1 & 0 & 1 & 0 & 0 & 0 & 1 & 0 & 0 & 0 & 0 \\
$\mathbf{M}_{\mathbf{2 1}}$ & 1 & 0 & 1 & 1 & 0 & 1 & 1 & 0 & 0 & 1 & 1 & 0 & 0 & 1 & 0 & 0 & 0 & 0 & 1 & 1 \\
$\mathbf{M}_{31}$ & 0 & 1 & 0 & 1 & 0 & 1 & 0 & 1 & 1 & 0 & 0 & 1 & 0 & 0 & 0 & 0 & 1 & 0 & 0 & 0 \\
$\mathbf{M}_{41}$ & 0 & 0 & 0 & 0 & 1 & 0 & 0 & 0 & 1 & 0 & 1 & 0 & 1 & 0 & 1 & 0 & 0 & 1 & 0 & 0 \\
\hline
\end{tabular}

Table 9. Machining time on alternative tools $\left(T_{i j}\right)$ for parts

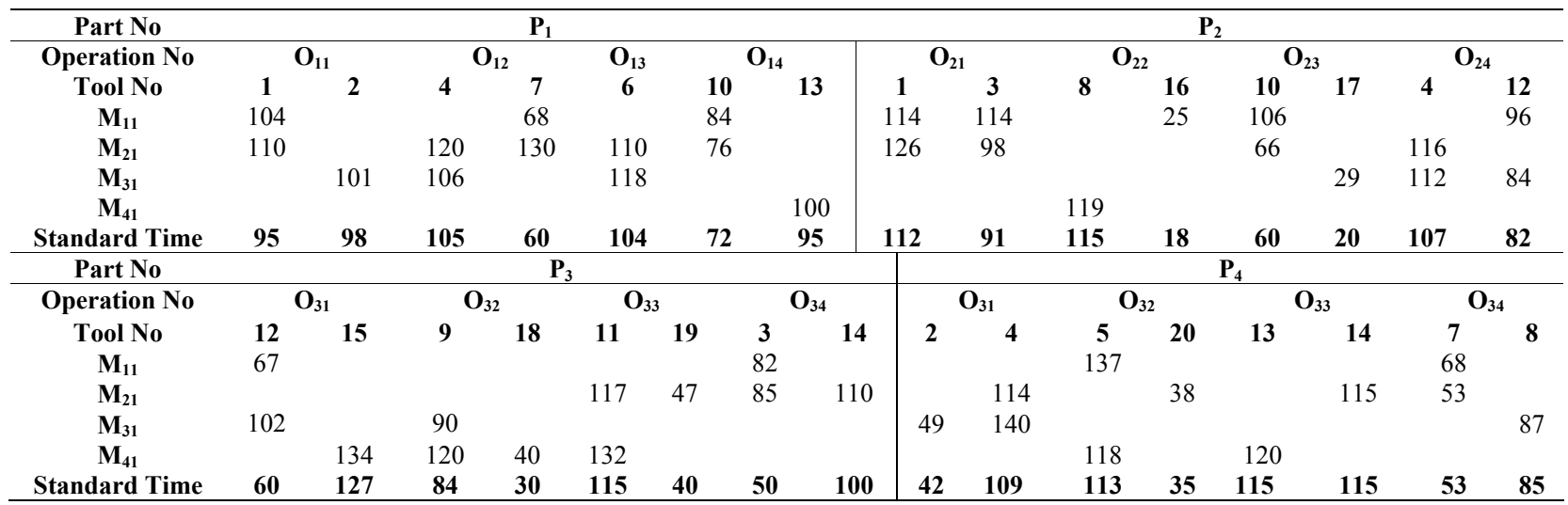

Table 10. Machining efficiency for parts on alternative tools

\begin{tabular}{|c|c|c|c|c|c|c|c|c|c|c|c|c|c|c|c|c|}
\hline \multirow{3}{*}{$\begin{array}{c}\text { Order No } \\
\text { Operation No } \\
\text { Tool No }\end{array}$} & \multicolumn{7}{|c|}{$\mathbf{P}_{1}$} & \multicolumn{9}{|c|}{$\mathbf{P}_{2}$} \\
\hline & \multicolumn{2}{|c|}{$\mathbf{O}_{11}$} & \multicolumn{2}{|c|}{$\mathbf{O}_{12}$} & $\mathbf{O}_{13}$ & \multicolumn{2}{|r|}{$\mathbf{O}_{14}$} & \multicolumn{3}{|c|}{$\mathbf{O}_{21}$} & \multicolumn{2}{|c|}{$\mathbf{O}_{22}$} & \multicolumn{2}{|c|}{$\mathbf{O}_{23}$} & \multicolumn{2}{|c|}{$\mathbf{O}_{24}$} \\
\hline & 1 & 2 & 4 & 7 & 6 & 10 & 1. & 1 & & 3 & 8 & 16 & 10 & 17 & 4 & 12 \\
\hline$O E_{11}(\%)$ & 91 & & & 88 & & 86 & & 98 & & 80 & & 70 & 56 & & & 85 \\
\hline$O E_{21}(\%)$ & 86 & & 88 & 46 & 95 & 95 & & 89 & & 93 & & & 91 & & 91 & \\
\hline $\mathrm{OE}_{31}(\%)$ & & 97 & 99 & & 88 & & & & & & & & & 69 & 95 & 98 \\
\hline $\mathrm{OE}_{41}(\%)$ & & & & & & & 9 & & & & 96 & & & & & \\
\hline Standard Time & 95 & 98 & 105 & 60 & 104 & 72 & 9 & 112 & & 91 & 115 & 18 & 60 & 20 & 107 & 82 \\
\hline Order No & \multicolumn{8}{|c|}{$\mathbf{P}_{3}$} & \multicolumn{8}{|c|}{$\mathbf{P}_{4}$} \\
\hline Operation No & \multicolumn{2}{|c|}{$\mathbf{O}_{31}$} & \multicolumn{2}{|c|}{$\mathbf{O}_{32}$} & \multicolumn{2}{|c|}{$\mathbf{O}_{33}$} & \multicolumn{2}{|c|}{$\mathbf{O}_{34}$} & & $\mathbf{O}_{41}$ & \multicolumn{2}{|c|}{$\mathrm{O}_{42}$} & \multicolumn{2}{|c|}{$\mathbf{O}_{43}$} & \multicolumn{2}{|c|}{$\mathbf{O}_{44}$} \\
\hline Tool No & 12 & 15 & 9 & 18 & 11 & 19 & 3 & 14 & 2 & 4 & 5 & 20 & 13 & 14 & 7 & 8 \\
\hline $\mathrm{OE}_{11}(\%)$ & 90 & & & & & & 61 & & & & 82 & & & & 78 & \\
\hline $\mathrm{OE}_{21}(\%)$ & & & & & 98 & 85 & 59 & 91 & & 96 & & 92 & & 100 & 100 & \\
\hline $\mathrm{OE}_{31}(\%)$ & 59 & & 93 & & & & & & 86 & 78 & & & & & & 98 \\
\hline $\mathrm{OE}_{41}(\%)$ & & 95 & 70 & 75 & 87 & & & & & & 96 & & 96 & & & \\
\hline Standard Time & 60 & 127 & 84 & 30 & 115 & 40 & 50 & 100 & 42 & 109 & 113 & 35 & 115 & 115 & 53 & 85 \\
\hline
\end{tabular}

Table 11. Operation assignment and task proportion $\left(\rho_{i j k l}\right)$ and tool load

\begin{tabular}{|c|c|c|c|c|c|}
\hline \multicolumn{2}{|c|}{ Part/Machine } & \multirow{2}{*}{$\begin{array}{c}\mathbf{M}_{11} \\
0.27(1)\end{array}$} & \multirow{2}{*}{$\mathbf{M}_{21}$} & \multirow{2}{*}{$\begin{array}{c}\mathbf{M}_{31} \\
0.73(2)\end{array}$} & \multirow{2}{*}{$\mathbf{M}_{41}$} \\
\hline $\mathbf{P}_{1}$ & $O_{11}$ & & & & \\
\hline & $O_{12}$ & $0.81(7)$ & & 0.19 (4) & \\
\hline & $\mathbf{O}_{13}$ & & $0.78(6)$ & $0.22(6)$ & \\
\hline & $O_{14}$ & $0.12(10)$ & $0.88(10)$ & & \\
\hline \multirow{4}{*}{$\mathbf{P}_{2}$} & $\mathbf{O}_{21}$ & $0.89(1)$ & $0.11(3)$ & & \multirow{3}{*}{$0.21(8)$} \\
\hline & $\mathbf{O}_{22}$ & $0.79(16)$ & & & \\
\hline & $\mathbf{O}_{23}$ & & $0.75(10)$ & $0.25(17)$ & \\
\hline & $\mathbf{O}_{24}$ & $0.22(12)$ & & $0.78(12)$ & \\
\hline \multirow[t]{4}{*}{$\mathbf{P}_{3}$} & $\mathrm{O}_{31}$ & $0.91(12)$ & & 0.09 (12) & \multirow{3}{*}{$0.21(18)$} \\
\hline & $\mathrm{O}_{32}$ & & & $0.79(9)$ & \\
\hline & $\mathrm{O}_{33}$ & & $1(19)$ & & \\
\hline & $\mathbf{O}_{34}$ & $0.35(3)$ & $0.65(14)$ & & \multirow{5}{*}{$0.52(5)$} \\
\hline \multirow[t]{4}{*}{$\mathbf{P}_{4}$} & $\mathbf{O}_{41}$ & & $0.66(4)$ & $0.34(2)$ & \\
\hline & $\mathbf{O}_{42}$ & & $0.48(20)$ & & \\
\hline & $\mathbf{O}_{43}$ & & $1(12)$ & & \\
\hline & $\mathbf{O}_{44}$ & $0.45(7)$ & $0.33(7)$ & $0.22(8)$ & \\
\hline
\end{tabular}


Development of a Simulation-Based Intelligent Decision Support System for the Adaptive

Real-Time Control of Flexible Manufacturing Systems

Table 12. Difference between the proposed method and the heuristic method of [43]

\begin{tabular}{ccccc}
\hline & $\begin{array}{c}\text { Total Actual } \\
\text { Cycle Time }\end{array}$ & $\begin{array}{c}\text { Total Idle } \\
\text { Time }\end{array}$ & $\begin{array}{c}\text { Total Time between } \\
\text { Departure }\end{array}$ & $\begin{array}{c}\text { Total Waiting } \\
\text { Time }\end{array}$ \\
\hline $\begin{array}{c}\text { Proposed system } \\
\text { Classis mathematical } \\
\text { method }\end{array}$ & 2703 & 441 & 35 & $\begin{array}{c}\text { Penalty } \\
\text { (Earliness) } \\
154 \\
\text { (Tardiness) }\end{array}$ \\
\hline
\end{tabular}

Table 13. Statistical analysis of difference between the proposed and mathematical method

\begin{tabular}{|c|c|c|c|c|c|}
\hline & & $\begin{array}{c}\text { Actual Cycle } \\
\text { Time }\end{array}$ & Idle Time & $\begin{array}{c}\text { Time between } \\
\text { Departure }\end{array}$ & $\begin{array}{c}\text { Waiting } \\
\text { Time }\end{array}$ \\
\hline \multirow{3}{*}{$\begin{array}{c}\text { Sample } \\
\text { Size }=384\end{array}$} & Mean & 2705.68 & 442.936 & 34.360 & 128.226 \\
\hline & SEMean & 0.85 & 0.507 & 0.104 & 0.533 \\
\hline & T-Value & -472.54 & -568.36 & -276.55 & -628.64 \\
\hline
\end{tabular}

Table 10 represents machining efficiency of operation allocation on alternative tools.

It is assumed that due date $(D D=2800), \alpha_{i}=\beta_{i}=0.5$, and $L I B_{k l}=L O B_{k l}=15$. Tool magazine capacity and tool life are considered 20 and 100, respectively. Manufacturing execution system also includes dispatching rules $(S P T)$, tooling strategies $(F C F S)$ and machining rules $(S Q L)$. Table 11 shows the operation assignment and task proportion according to the rules of the proposed method.

Table 12 represents the difference of total actual cycle time, total idle time, total time between departures and total waiting time between the proposed rule-based system and the mathematical method.

The solution obtained from proposed method creates a balanced and controlled actual cycle time on machining centers. The proposed approach outperforms the heuristic method in terms of the total actual cycle time, total idle time, total time between departures and total waiting time. The proposed system presents 48.5 units of earliness penalty despite the 154 unit of tardiness penalty of mathematical method. To show the effects of difference between the proposed method outputs and classic mathematical method, statistical analysis is given as shown in Table 13.

The aforementioned results verify and validate the FMS shop floor links to the supervisory control of machine and tool flexibility. Different scenarios of performance criteria levels demonstrate effectiveness of the proposed method for the system control. The proposed method is also efficient in terms of the computation time which is highly important for the real time control of a manufacturing system. The proposed real-time simulation-based intelligent decision support system provides a real time control mechanism for improving performance of a flexible manufacturing shop floor.

\section{Conclusions}

This paper presents an intelligent decision support system to tackle the production control of a FMS. Development of the present knowledge-based system is aimed at integrating an ECA rule-based system and a simulator module to ease the cell adaptive supervisory control. A novel architecture of this intelligent adaptive controller prototype which is based on a real-time simulator core has been developed and presented to validate the proposed approach.

The FMS shop floor data are gathered and stored into the appropriate databases over time. The adaptive control mechanism employs a real time discrete event simulator to predict performance of the given system during the remaining time of planning horizon. The current state of the FMS performance criteria from the simulator is then stored on the appropriate databases. The proposed method provides an applicable and efficient framework for real-time control of the shop floor in flexible manufacturing system. The criteria considered to measure performance of the system shows that the proposed approach is effective and efficient in controlling shop floor. The main contributions of this paper can be summarized as follows.

1) Designing real time ECA rules according to feed forward reasoning with the high degree of granularity.

2) Reinforcement of the expert system reasoning technique using data mining and knowledge-elicitation techniques.

3) Proposed method constitutes the framework of adaptive controller supporting the co-ordination and cooperation relations by integrating a real time simulator and an IDSS for implementing dynamic strategies.

4) Avoiding ineffective redundancy at concurrent firing of rules and high degree of parallelism

5) The simulation based IDSS uses a posteriori adap- 
tive control mechanism that also is an online control method acting after the event occurs versus such popular reactive control method.

As a result, the proposed system is suitable for different control frameworks on an existing flexible manufacturing system considering the physical constraints and the production objectives. Furthermore, the system illustrates the potential of using the intelligent rule-based DSS for adaptive control of modern industrial plants. Future researches may concentrate on the application of other types of flexibility in shop floors using simulationbased predictive controllers.

\section{REFERENCES}

[1] J. A. Buzacott and D. D. Yao, "Flexible Manufacturing Systems: A Review of Analytical Models," Management Science, Vol. 32, No. 7, 1986, pp. 890-905.

[2] J. R. Dixon, "Measuring Manufacturing Flexibility: An Empirical Investigation," European Journal of Operational Research, Vol. 60, 1992, pp. 131-143.

[3] R. Jaikumar, "Flexible Manufacturing Systems: Management Perspective," Division of Research, Harvard Business School, 1984.

[4] J. S. Edghill and A. Davies, "Flexible Manufacturing Systems - The Myth and Reality," International Journal of Advanced Manufacturing Technology, Vol. 1, No. 3, 1985, pp. 37-54.

[5] M. D. Byrne and P. Chutima, "Real-Time Operational Control of an FMS with Full Routing Flexibility," International Journal of Production Economics, Vol. 51, No. 2, 1997, pp. 109-113.

[6] Y. M. Moon, "Reconfigurable Machine Tool Design," In: A. I. Dashchenko, Ed., Reconfigurable Manufacturing Systems and Transformable Factories, Springer, 2006, pp. 112-139.

[7] R. Tawegoum, E. Castelain and J. C. Gentina, "RealTime Piloting of Flexible Manufacturing Systems," European Journal of Operational Research, Vol. 78, No. 2, 1994, pp. 252-261.

[8] K. E. Stecke and L. Kim, "A Flexible Approach to Part Type Selection in Flexible Flow Systems Using Part Mix Ratios," International Journal of Production Research, Vol. 29, No. 1, 1991, pp. 53-75.

[9] C. Basnet and J. H. Mize, "Scheduling and Control of Flexible Manufacturing Systems: A Critical Review," International Journal of Computer Integrated Manufacturing, Vol. 7, No. 6, 1994, pp. 340-355.

[10] J. Ayel, "Supervising Conflicts in Production Management," International Journal of Computer Integrated Manufacturing, Vol. 8, No. 1, 1995, pp. 54-63.

[11] H. Seifoddini and J. Zhang, "Application of Simulation and Petri Net Modelling in Manufacturing Control Systems," International Journal of Production Research, Vol. 34, No. 1, 1996, pp. 191-207.
[12] E. Szelke and L. Monostori, "Reactive Scheduling in Real-Time Production Control," Modeling Manufacturing Systems, Springer, New York, 1999.

[13] Z. Guo, W. Wong, S. Leung, J. Fan and S. Chan, "A Genetic-Algorithm-Based Optimization Model for Scheduling Flexible Assembly Lines," International Journal of Advanced Manufacturing Technology, Vol. 36, No. 1-2, 2006, pp. 156-168

[14] D. J. Van der Zee, "Modeling Decision Making and Control in Manufacturing Simulation," International Journal of Production Economics, Vol. 100, No. 1, 2006, pp. 155-167.

[15] F. T. S. Chan, R. Bhagwat and S. Wadhwa, "Comparative Performance Analysis of a Flexible Manufacturing System (FMS): A Review-Period-Based Control," International Journal of Production Research, Vol. 46, No. 1, 2006, pp. 1-24.

[16] G. Habchi and C. Berchet, "A Model for Manufacturing Systems Simulation with a Control Dimension," Simulation Modelling Practice and Theory, Vol. 11, No. 1, 2003, pp. 21-44.

[17] B. P. Douglass, "Real-Time Design Patterns: Robust Scalable Architecture for Real-Time Systems," AddisonWesley, 2003.

[18] L. Yao, W. Browne, I. Postlethwaite, T. Ozen, P. Atack, M. Mar and S. Lowes, "Architecture for Intelligent Knowledge-Based Supervisory Control of Rolling Mills," IFAC Workshop on New Technologies for Automation of Metallurgical Industry, Shanghai, China, 2003, pp. 162167.

[19] G. Guariso, M. Hitz and H. Werthner, "An Integrated Simulation and Optimization Modelling Environment for Decision Support," Decision Support Systems, Vol. 16, No. 2, 1996, pp. 103-117.

[20] C. Gertosio, N. Mebarki and A. Dussauchoy, "Modeling and Simulation of the Control Framework on a Flexible Manufacturing System," International Journal of Production Economics, Vol. 64, No. 1-3, 2000, pp. 285293.

[21] J. W. Fowler and O. Rose, "Grand Challenges in Modeling and Simulation of Complex Manufacturing Systems," SIMULATION-Transactions of the Society for Modelling and Simulation International, Vol. 80, No. 9, 2004, pp. 469-476.

[22] F. T. S. Chan and H. Chan, "A Comprehensive Survey and Future Trend of Simulation Study on FMS Scheduling," Journal of Intelligent Manufacturing, Vol. 15, No. 1, 2004, pp. 87-102.

[23] G. R. Drake, J. S. Smith and B. A. Peters, "Simulation as a Planning and Scheduling Tool for Flexible Manufacturing Systems," Proceedings of the 1995 Winter Simulation Conference, 1995, pp. 805-812.

[24] F. T. S. Chan, H. K. Chan and H. C. W. Lau, "The State of the Art in Simulation Study on FMS Scheduling: A Comprehensive Survey," International Journal of Ad- 
vanced Manufacturing Technology, Vol. 19, No. 11, 2002, pp. 830-849.

[25] S. Chong, A. Sivakumar and R. Gay, "Simulation-Based Scheduling for Dynamic Discrete Manufacturing," Proceedings of the 2003 Winter Simulation Conference, New Orleans, Louisiana, USA, 2003.

[26] R. W. Brennan and O. William, "Performance Analysis of a Multi-Agent Scheduling and Control System for Manufacturing," Production Planning Control, Vol. 15, No. 2, 2004, pp. 225-235.

[27] R. Schelasin and J. Mauer, "Creating Flexible Simulation Models,” IEE Solutions, Vol. 5, 1995, pp. 50-67.

[28] A. Anglani, A. Grieco, M. Pacella and T. Tolio, "ObjectOriented Modeling and Simulation of Flexible Manufacturing Systems: A Rule-Based Procedure," Simulation Modelling Practice and Theory, Vol. 10, No. 3-4, 2002, pp. 209-234.

[29] D. Arnott and G. Pervan, "A Critical Analysis of Decision Support Systems Research," Journal of Information Technology, Vol. 20, No. 2, 2005, pp. 67-87

[30] R. W. Brennan, "Towards Real-Time Distributed Intelligent Control: A Survey of Research Themes and Applications," IEEE Transactions on Systems, Man, and Cybernetics, Vol. 37, No. 5, 2007, pp. 744-765.

[31] G. E. Vieira, J. W. Herrmann and E. Lin, "Rescheduling Manufacturing Systems: A Framework of Strategies, Policies, and Methods," Journal of Scheduling, Vol. 6, No. 1, 2003, pp. 39-62.

[32] J. A. Ventura, F. F. Chen and C. H. Wu, "Grouping Parts and Tools in FMS Production Planning," International Journal of Production Research, Vol. 28, No. 6, 1990, pp. 1039-1056.

[33] R. Beach, A. Muhlemann, D. Price, A. Paterson and J. Sharp, "A Review of Manufacturing Flexibility," European Journal of Operational Research, Vol. 122, No. 1, 2000, pp. 41-57.

[34] P. Kouvelis, "An Optimal Tool Selection Procedure for the Initial Design Phase of a Flexible Manufacturing Sys- tem," European Journal of Operational Research, Vol. 55, No. 2, 1991, pp. 201-210.

[35] P. Tomek, “Tooling Strategies Related to FMS Management," FMS Magazine, Vol. 4, 1986, pp. 102-107.

[36] D. Veeramani, D. Upton and M. Barash, "Cutting Tool Management in Computer Integrated Manufacturing," The International Journal of Flexible Manufacturing Systems, Vol. 3, No. 4, 1992, pp. 237-265.

[37] M. Wahab, "Measuring Machine and Product Mix Flexibilities of a Manufacturing System," International Journal of Production Research, Vol. 43, No. 18, 2005, pp. 3773-3786.

[38] J. Browne, D. Dubois, K. Rathmill, S. Sethi and K. Stecke, "Classification of Flexible Manufacturing Systems," The FMS Magazine, Vol. 2, No. 2, 1984, pp. 114117.

[39] J. A. Buzacott, "The Fundamental Principles of Flexibility in Manufacturing Systems," Proceedings of the 1 st International Conference on Flexible Manufacturing Systems, 1982, pp. 13-22.

[40] S. K. Das and P. Nagendra, "Investigation into the Impact of Flexibility on Manufacturing Performance," International Journal of Production Research, Vol. 31, No. 10, 1993, pp. 2337-2354.

[41] A. Gray, A. Seidmann and K. Stecke, "A Synthesis of Decision Models for Tool Management in Automated Manufacturing," Management Science, Vol. 39, No. 5, 1993, pp. 549-567.

[42] N. Buyurgan, C. Saygina and E. Kilic, "Tool Allocation in Flexible Manufacturing Systems with Tool Alternatives," Robotics and Computer-Integrated Manufacturing, Vol. 20, No. 4, 2004, pp. 341-349.

[43] S. C. Sarin and C. S. Chen, "The Machine Loading and Tool Allocation in a Flexible Manufacturing System," International Journal of Production Research, Vol. 25, No. 7, 1987, pp. 1081-1094. 